\title{
Transmission of chlamydial infections to sexual partners
}

\author{
ANNE-MARIE WORM AND CARSTEN SAND PETERSEN
}

From the Department of Dermatovenereology, Bispebjerg Hospital, Copenhagen, Denmark

SUMMARY The incidence of chlamydial infections was studied in 33 male and 48 female regular sexual partners of 81 patients attending a sexually transmitted disease clinic who had chlamydial infections. Chlamydia trachomatis was isolated from $42 \%$ of the male partners and $62 \%$ of the female partners $(p>0.05)$. The number of infected partners was independent of the incidence of sexual intercourse and of the presenting symptoms. The use of condoms was the only contraceptive method that seemed to lower the risk of transmission of chlamydial infection.

If diagnostic facilities for $C$ trachomatis are not available, and sexual partners of patients with chlamydial infection are treated epidemiologically, a high proportion of both men and women may be treated unnecessarily.

\section{Introduction}

Chlamydia trachomatis is the most common sexually transmitted cause of urethritis, and the number of genitourinary chlamydial infections exceeds those caused by Neisseria gonorrhoeae. The risk of acquiring chlamydial infection from an infected sexual partner has only been addressed in few studies. ${ }^{12}$ One reason could be that contact tracing is usually omitted in chlamydial infections, in contrast to gonococcal infections. The sexual partner of a patient with genitourinary chlamydial infections is often treated epidemiologically without attempting to confirm chlamydial infection in the partner. If the risk of chlamydial infection is only $25 \%$ for the male partner and $53 \%$ for the female partner as stated in a previous study, ${ }^{1}$ epidemiological treatment should not be routine.

This study was therefore performed to elucidate further the incidence of chlamydial infections in regular sexual partners of men and women with genitourinary chlamydial infections.

\section{Patients and methods}

At the Copenhagen outpatient clinic for sexually transmitted diseases (STD) all women are investigated

Address for reprints: $\mathrm{Dr}$ Anne-Marie Worm, Department of Dermatovenereology, Bispebjerg Hospital, DK-2400 Copenhagen NV, Denmark

Accepted for publication 2 May 1986 routinely for urethral and cervical chlamydial infections at their first visit to the clinic. Furthermore, material for culture for $C$ trachomatis is obtained from all men with urethritis and from sexual contacts of patients with chlamydial infections. $C$ trachomatis infection is diagnosed by a conventional culture method. $^{3}$

During a three month period from April to July 1985 men and women with a proved chlamydial infection were asked to give their regular sexual partner written information about chlamydial infections and to invite them to attend the clinic for examination. A sexual partner was regarded as being regular if a relationship had lasted for more than one month. When attending the clinic, sexual partners were asked about methods of contraception and about the incidence of sexual intercourse during the preceding month. Patients and partners who had used antibiotics during the previous month were excluded.

\section{Results}

The partners of 81 patients with chlamydial infections accepted the invitation to attend the clinic for examination and fulfilled the criteria for evaluation. The table shows the results obtained from the 33 men and 48 women. $C$ trachomatis was isolated from $63 \%$ of the women and $42 \%$ of the men. The risk of harbouring $C$ trachomatis was somewhat higher in women than in men, but the difference was not significant $\left(X^{2}\right.$ test, $\mathrm{p}>0.05$ ).

As shown in the table, there was no correlation 19 
TABLE Recovery of Chlamydia trachomatis from regular sexual partners of 48 men and 33 women with chlamydial infections, related to use of contraceptives, incidence of sexual intercourse in preceding month, and presence of urethritis or discharge, or both

\begin{tabular}{|c|c|c|c|c|}
\hline & \multicolumn{2}{|c|}{ No (\%) of men $(n=33)$ : } & \multicolumn{2}{|c|}{ No (\%) of women $(n=48)$ : } \\
\hline & $\begin{array}{l}\text { Positive } \\
14 \text { (42) }\end{array}$ & $\begin{array}{l}\text { Negative } \\
19 \text { (58) }\end{array}$ & $\begin{array}{l}\text { Positive } \\
30 \text { (63) }\end{array}$ & $\begin{array}{l}\text { Negative } \\
18(38)\end{array}$ \\
\hline $\begin{array}{l}\text { Contraceptive method: } \\
\text { Oral } \\
\text { Intrauterine device } \\
\text { Condom }\end{array}$ & $\begin{array}{l}9(64) \\
5(36) \\
0\end{array}$ & $\begin{array}{l}9(47) \\
3(16) \\
3(16)\end{array}$ & $\begin{array}{r}13(43) \\
7(23) \\
4(13)\end{array}$ & $\begin{array}{l}6(33) \\
3(17) \\
6(33)\end{array}$ \\
\hline $\begin{array}{l}\text { Incidence of sexual int } \\
\text { None } \\
>5 \\
<5\end{array}$ & $\begin{array}{l}\text { s month: } \\
0 \\
4(29) \\
10(71)\end{array}$ & $\begin{array}{r}4(21) \\
5(26) \\
14(74)\end{array}$ & $\begin{array}{r}6(20) \\
15(50) \\
15(50)\end{array}$ & $\begin{array}{r}3(17) \\
11(61) \\
7(39)\end{array}$ \\
\hline $\begin{array}{l}\text { Genitourinary symptor } \\
\text { Present } \\
\text { Absent }\end{array}$ & $\begin{array}{l}6(43) \\
8(57)\end{array}$ & $\begin{array}{r}8(42) \\
11(58)\end{array}$ & $\begin{array}{l}13(43) \\
17(57)\end{array}$ & $\begin{array}{r}8(44) \\
10(56)\end{array}$ \\
\hline
\end{tabular}

incidence of sexual intercourse during the preceding month) and the number of partners who had chlamydial infection. The use of a condom was the only contraceptive method that seemed to lower the risk of infection with $C$ trachomatis; chlamydiae were cultured from only $31 \%$ of sexual partners of condom users compared with $67 \%$ of sexual partners using an intrauterine contraceptive device (IUCD) and $60 \%$ of those using an oral contraceptive. The differences, however, were not significant ( $p>0.05$ ).

Symptoms compatible with chlamydial infection (see table) were equally common in men and women whether they yielded chlamydiae or not.

\section{Discussion}

The risk of transmitting chlamydial infections to sexual partners has been investigated by Lycke et $a l,{ }^{1}$ who found that $25 \%$ of men and $53 \%$ of women partners harboured $C$ trachomatis. In two other studies the incidence of chlamydial infections was $64 \%$ in female partners of men with chlamydial urethritis ${ }^{2}$ and $43 \%$ in female partners of men with non-gonococcal urethritis (NGU). ${ }^{4}$

The incidence (63\%) of chlamydial infections of the female partners in the study published here was thus close to these findings. The percentage of male partners $(42 \%)$ in our study who were chlamydia positive by culture was, however, higher than that found by Lycke et $a l,{ }^{1}$ and furthermore was not appreciably different from that of the female partners. The higher infection rate of male partners in this study may have been due to patient selection. Lycke et al examined all recent sexual partners, ${ }^{1}$ whereas we examined only regular (for more than one month) sexual partners.

It seems likely therefore that the incidence of chlamydial infections in sexual partners of patients attending an STD clinic does not differ appreciably between men and women. Symptoms did not help to indicate which of the sexual partners harboured $C$ trachomatis, and the incidence of sexual intercourse did not affect the number of partners with chlamydial infections.

The only contraceptive that seemed to lower the transmission of $C$ trachomatis to both male and female partners was the condom. Hilton et al found a higher percentage of chlamydial infections in women using oral contraceptives, ${ }^{5}$ and Lycke et al found an association between the use of the IUCD and chlamydial infections. ${ }^{1}$ In our study, however, the incidence of chlamydial infections in female partners using oral contraceptives was similar to the incidence in those using IUCDs.

The risk of transmitting $N$ gonorrhoeae to sexual partners was not examined in this study. In the study of Lycke et al however, $82 \%$ of the female and $79 \%$ of the male partners of patients with gonococcal infection were also infected. ${ }^{1}$ The risk of transmitting gonorrhoea thus seems to be somewhat higher than the risk of transmitting chlamydial infection.

In the case of gonorrhoea, most countries advocate contact tracing and treatment of sexual partners only when the organism is identified, even though $80 \%$ of partners will be infected. In contrast, chlamydial infections seem to be managed differently, not only from one country to another, but also within a country. In Denmark there is legislation about gonococcal but not about chlamydial infection. This fact however, should not hinder the appropriate management of both these infections.

It is well known that in patients attending STD clinics the number with chlamydial infections exceeds that with gonorrhoea and that the consequences of untreated chlamydial infections may be serious. As most women and $25 \%$ of men with chlamydial infection are symptomless, ${ }^{6}$ screening both men and women 
for $N$ gonorrhoeae and $C$ trachomatis should be routine at the first attendance at an STD clinic. Furthermore, it should be routine to contact trace all sexual partners of patients with chlamydial infection.

A lack of laboratory diagnostic facilities for $C$ trachomatis and the cost of establishing such facilities have contributed to the difficulties in establishing routine screening for chlamydiae in many areas. Under such circumstances it may be necessary to treat men with NGU and their female partners without attempting to identify the organism in genital material. If this is done about $40 \%$ of female and $60 \%$ of male partners may be treated unnecessarily. During the past few years direct diagnostic tests for $C$ trachomatis using polyclonal and monoclonal antibodies have been evaluated. These tests are quick, simple, and highly specific and sensitive, ${ }^{7-9}$ and they give an opportunity to establish a diagnostic service for $\boldsymbol{C}$ trachomatis.

\section{References}

1. Lycke E, Löwhagen G-B, Hallhagen G, Johannisson G, Ramstedt K. The risk of transmission of genital Chlamydia trachomatis infection is less than that of genital Neisseria gonorrhoeae infection. Sex Transm Dis 1980;7:6-10. .

2. Paavonen J, Kousa M, Saikku P, Vesterinen E, Jansson E, Lassus A. Examination of men with nongonococcal urethritis and their sexual partners for Chlamydia trachomatis and Ureaplasma urealyticum. Sex Transm Dis 1978;5:93-6.

3. Ripa KT, Mårdh P-A. New simplified culture technique for Chlamydia trachomatis. In: Hobson D, Holmes KK, eds. Nongonococcal urethritis and related infections. Washington DC: American Society for Microbiology, 1977:323-7.

4. Bradley MG, Hobson D, Lee N, Tait IA, Rees E. Chlamydial infections of the urethra in women. Genitourin Med 1985;61:371-5.

5. Hilton AL, Richmond SJ, Milne JD, Hindley F, Clarke SKR. Chlamydia A in the female genital tract. British Journal of Venereal Diseases 1974;50:1-10.

6. Stamm WE, Koutsky LA, Benedetti JK, Jourden JL, Brunham RC, Holmes KK. Chlamydia trachomatis urethral infections in men. Ann Intern Med 1984;100:47-51.

7. Tam MR, Stamm WE, Handsfield $\mathrm{HH}$, et al. Culture independent diagnosis of Chlamydia trachomatis using monoclonal antibodies. N Engl J Med 1984;310:1146-50.

8. Jones MF, Smith TF, Houglum AJ, Herrmann JE. Detection of Chlamydia trachomatis in genital specimens by the Chlamydiazyme test. J Clin Microbiol 1984;20:465-6.

9. Teare EL, Sexton C, Lim F, McManus T, Cuttley AH, Hodgson J. Conventional tissue culture compared with rapid immunofluorescence for identifying Chlamydia trachomatis in specimens from patients attending a genitourinary clinic. Genitourin Med 1985;61:379-82. 